\title{
Finding the connection between research and design: the knowledge development of STEM teachers in a professional learning community
}

\author{
T. E. Vossen ${ }^{1,2}$ D $\cdot$ I. Henze ${ }^{2} \cdot$ M. J. De Vries ${ }^{2} \cdot$ J. H. Van Driel ${ }^{1,3}$ (D)
}

Accepted: 23 February 2019 / Published online: 6 March 2019

(c) The Author(s) 2019

\begin{abstract}
Research and design activities are becoming more important in Science, Technology, Engineering and Mathematics (STEM) and D\&T (design and technology) education. Research and design are often taught separately from each other, while in professional STEM practices, many projects are neither 'research only' or 'design only'-they are both. In this study, we aimed to provide insights in teachers' personal and shared knowledge on how research and design can be connected. To this end, we examined the development of pedagogical content knowledge (PCK) and beliefs of six teachers of the Dutch STEM subject $\mathrm{O} \& \mathrm{O}$ (research and design), who participated in a professional learning community (PLC) aimed at connecting research and design within this subject. Results of pre and post-PLC interviews showed that teachers' personal PCK was very diverse, probably due to their different beliefs, backgrounds and teaching contexts. Through jointly designing instructional strategies for connecting research and design, teachers contributed to a collective knowledge base. The results of this study indicate that a professional learning community in which teachers with varying backgrounds construct knowledge and instructional strategies together, can be a powerful method to enhance personal PCK and collective knowledge. These are promising outcomes in the light of shaping professional development activities for STEM and D\&T teachers, which in turn aims to provide students with a holistic and realistic view on current professional STEM fields.
\end{abstract}

Keywords Research · Design · Connection · STEM - Secondary education · PCK · Personal PCK $\cdot$ Collective knowledge $\cdot$ Beliefs

\section{Introduction}

Research and design activities are considered core processes in STEM (Science, Technology, Engineering and Mathematics) and D\&T (design and technology) education (NGSS 2013; NRC Framework 2012; ITEA 2007). Research and design activities are often implemented in STEM education as short-term projects, and often these projects

T. E. Vossen

t.e.vossen@iclon.leidenuniv.nl

Extended author information available on the last page of the article 
specifically focus on researching or designing only. In reality, however, research and design activities overlap and connect within STEM professions (Sanders and Stappers 2008). Seeing the link between research and design and developing a view of the professional world in STEM are key learning goals mentioned in the NRC framework (2012, p. 42): "Engaging in the practices of engineering likewise helps students understand the work of engineers, as well as the links between engineering and science." Still, the practice of connecting science and engineering, or research and design, is not self-evident in education (Kolodner et al. 2003a; Van Breukelen et al. 2016). This gap between policy ("students should learn that research and design are connected in reality") and educational practice ("students conduct research projects and design projects separately") is to be bridged by the teacher. Often, D\&T teachers or science teachers are expected to teach these integrated STEM practices, however virtually none of these teachers have a background or experience in combining research/science with design/engineering (c.f. Love and Wells 2018). Furthermore, like design and technology, combining research and design activities is a less established practice in education, when compared for example to inquiry in science education, and does not have a well-established epistemology (De Vries 2006; Doyle et al. 2018). It is unexplored what STEM teachers' knowledge is about connecting research and design in the classroom. It is therefore of interest to understand teachers' (often implicitly held) beliefs about the connection between research and design (Doyle et al. 2018), and how they develop pedagogical content knowledge (PCK), or 'knowledge and beliefs' (Van Driel et al. 1998), about this practice (De Vries 2015; Engelbrecht and Ankiewicz 2016).

In this paper, we studied the knowledge development of teachers of the Dutch secondary school subject O\&O (the abbreviation for 'onderzoeken en ontwerpen', which is Dutch for 'research and design'), a STEM oriented subject that consists of authentic research and design projects in STEM fields provided by local companies, within a professional learning community (PLC) aimed at connecting research and design. The subject O\&O is a form of STEM education because it combines research projects (related to the Science component of STEM) and design projects (related to the Technology and Engineering components of STEM), and because the O\&O projects all have STEM-related contexts (for example in the fields of architecture, industrial design or biology). As O\&O is a relatively new and innovative subject, it is important to know the perceptions of teachers of the practices related to research and design, because teachers are the biggest influence on successfully implementing a new curriculum (Van Driel et al. 2001). While there are several studies trying to connect science and engineering (Apedoe et al. 2008), or science content to design activities (van Breukelen et al. 2016), studies on teacher knowledge about connecting research and design activities are scarce. With this study, we aimed to conduct a qualitative exploration of what teachers' personal PCK and beliefs on connecting research and design are, and how they develop over the course of a PLC. Several studies have stretched the importance of arranging professional development in the form of "communities of learning", where the expertise of teachers and experts meet to support meaningful shifts of practice (Butler et al. 2004; Hultén and Björkholm 2016). The notion that teachers construct their knowledge partly based on their existing knowledge and beliefs, and partly based on their participation in a learning community where they develop shared meanings, is consistent with constructivist learning theory (Borko et al. 1997). By bringing together teachers with varying backgrounds, we attempted to better understand their collective meaning making of the connection between research and design, through analyzing shared products they developed together. Therefore, our research questions are: 
1. How can the development of teachers' personal PCK and beliefs about connecting research and design be characterized before and after a PLC?

2. How did teachers collectively give meaning to the connection between research and design during the PLC?

\section{Theoretical framework}

Research and design are often connected to each other, however both activities have separate goals and histories (Williams et al. 2012). Research is conducted by collecting and analysing data, to explore, explain or compare certain conditions (Creswell 2008). The goal of design activities is to develop or improve products or services (De Vries 2005). Many models of the research process and the design process have been described in literature (for example see Kolodner et al. 2003a; Mehalik et al. 2008; Van Dooren et al. 2014; Willison and O'Regan 2008). As researching and designing are dynamic practices, they have no fully agreed upon consensus models within the community (Vezino 2018). It is not the purpose of this paper to give unambiguous definitions of research and design practices; however, we can mention a number of core elements for each activity. The research process generally consists of articulating a research question; generating hypotheses; planning the research; collecting data; organizing and analysing data; conclusions and discussion; and presenting the findings. The design process generally consists of clarifying the problem; assembling a program of requirements; planning the design; constructing a prototype; testing the prototype; optimizing the prototype; analysing the product; presenting the product to the client or target group. Research and design activities have thus quite similar structures and are both concerned with challenging, ill-structured problems or questions (Hathcock et al. 2015). Both processes are systematic, purposeful, tentative and both processes can inform each other (Vezino 2018). In the subject O\&O (Dutch abbreviation for 'Research and Design'), which forms the context of this study, learning outcomes of research projects are specified as: the candidate can, within contexts, analyze questions, use relevant concepts and theory, develop a discipline specific research, choose a suitable research method, conduct the research, and draw conclusions from the results while using relevant knowledge, consistent reasoning and relevant mathematical skills (SLO 2014). Learning outcomes of design projects within the subject O\&O are specified as: the candidate can, within contexts, expand a question into a design problem, choose a design method based on this problem, prepare, conduct, test and evaluate a technological design while using relevant concepts, theory, skills and valid and consistent reasoning (SLO 2014). As one of the aims of O\&O is to give students a realistic idea of what research and design projects look like within real STEM professions, it is important that students not only learn to conduct research and design projects separately, but also that these activities have similarities and can be connected to each other. Furthermore, it is necessary for students to include research activities within their design projects to enhance the quality of their designed decisions and rise above a trial-and-error approach (Burghardt and Hacker 2004; Crismond and Adams 2012).

Research and design activities can be connected and intertwined, enhancing and informing one another. For example, doing research and thereby gaining knowledge is part of, and even necessary for designing (Downton 2003; Frankel and Racine 2010; Sanders and Stappers 2008). De Jong and Van der Voordt (2002) view research and design as activities on a gliding scale between art and science, in which design activities without research activities are a form of 'intuitive design' and can almost be labelled as art. In the overlapping area 
between research and design, the connection between these two activities can take multiple forms. Frankel and Racine (2010) describe three mechanisms: research for design, research through design, and research about design. Research for design can be explained as research to enable design, such as using qualitative and quantitative methods to find characteristics of materials used for the product, establish regulations and standards, obtain data on human physical characteristics and understand human behavior (Downton 2003), but also user and usability testing. In research through design, the emphasis is on the research objective of creating design knowledge, not the project solution (Frankel and Racine 2010). In this case, the design itself helps to provide knew knowledge in a broader context. In research about design, one studies the design process-for example the history of design, design theory, and the analysis of design activity (Schneider 2007). Design activities can also play their part in a research process, for example, when designing a device to take measurements, or when designing experiments (Fallman 2003). In an educational context, the importance of conducting (scientific) research integrated within design projects has been mentioned in numerous studies (Apedoe et al. 2008; Kolodner et al. 2003b; Mehalik et al. 2008). Doing research or scientific inquiry is related to, and can be enhanced by the design process (Shernoff et al. 2017; Stohlmann et al. 2012). In her paper, Gunckel (2010) describes the application of the experiences-patterns-explanations (EPE) triangle (Anderson 2003), in which students must find patterns in their experiences with phenomena, and then attempt to explain those patterns. In the EPE triangle, doing research to discover patterns and theories is followed by application, for example by design. The cycles of research and design have a back and forth relationship in an integrated research and design lesson (Vezino 2018). Kolodner et al. (2003a) argue that this back and forth movement enhances students' learning of science through research and design activities.

In their approach to science education, called Learning By Design (LBD), Kolodner et al. (2003b) visualize this relationship between investigation (research) and design within STEM education (Fig. 1). They state that learning in the LBD cycle takes place through activities specific to investigating and designing. Whenever there is a 'need to know' during the design cycle, an investigation, or research, is conducted, in which students need to figure out which knowledge they need to complete the design challenge. The 'need to do', according to Kolodner et al. (2003a) consists of applying what students have learned through investigation in their design. In our study, we even take the interpretation of these two cycles one step further: students can move back and forth between the research

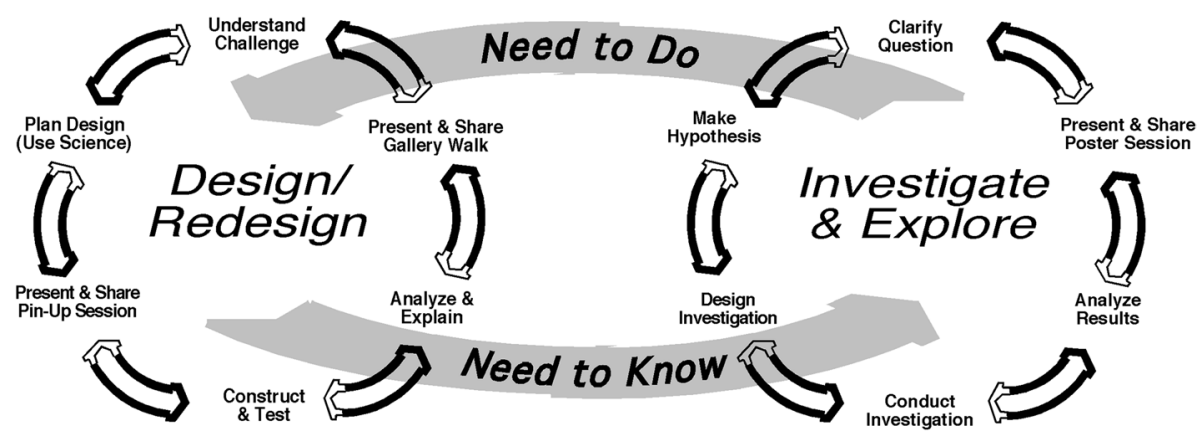

Fig. 1 The connection between the research and design cycles (Kolodner et al. 2003a), reprinted with permission of the authors 
and design cycle during the project, regardless whether the main focus of the project is researching or designing. Whenever students experience a 'need to know'-for example the need to know more about the topic of the design challenge, or about the users or target group - they move from the design cycle into the research cycle. Vice versa, whenever students experience a 'need to do' - the need to construct a measuring method, or the need to give practical recommendations that inform a product or service- they move from the research cycle into the design cycle.

Teachers need to be able to facilitate students in connecting the research and design cycles to each other. For that, they need specific knowledge and skills for guiding students in this practice, for which we will use the construct of pedagogical content knowledge (PCK). Shulman (1987) described this as: "that special amalgam of content and pedagogy that is uniquely the province of teachers, their own special form of professional understanding" (p. 8). The construct of PCK is often employed in topic-specific teaching contexts, for example: knowledge about chemical equilibrium in chemistry (Van Driel et al. 1998), or knowledge about photosynthesis in biology (Käpylä et al. 2009). However, PCK also applies to broader educational contexts, such as PCK about the practice of modelling (Henze et al. 2007; Justi and Van Driel 2005) or PCK about the Nature of Science (NOS) (Faikhamta 2013; Wahbeh and Abd-El-Khalick 2014). It is thus acknowledged in literature that PCK can be broad or narrow, and topic, discipline, or practice specific. In this study, we use the construct of PCK in a broad sense, meaning that the contents of PCK in our case are scientific practices (e.g. 'researching' and 'designing'). Content knowledge is a knowledge base essential for PCK (Gess-Newsome 2015). The teachers in our sample were expected to collectively possess basic content knowledge about research and design processes, as some of them had specific design backgrounds or experience with researching. In our study, the content of PCK is thus formed by the research and design processes, and we investigated teachers' knowledge about the teaching and learning of the connection between these research and design activities.

In the 2015 Consensus Model for PCK (Gess-Newsome 2015), PCK is influenced by other knowledge bases: the generic Teacher Professional Knowledge Bases (TPKB), like pedagogical knowledge and content knowledge, and Topic Specific Professional Knowledge (TSPK), which is dynamic and canonical knowledge constructed by experts and generated by research or best practice. In our study, the content of this knowledge base would be the research and design processes. These knowledge bases influence a teachers' personal PCK (pPCK), which is described as the knowledge of and reasoning behind teaching particular content, in a particular way, for a particular purpose, to particular students (GessNewsome 2015). pPCK is the teachers' unique and personal knowledge about teaching, informed by his/her beliefs and experiences, educational background, and interactions with others (Gess-Newsome 2015). Since the teachers in this study were interviewed about their personal knowledge before and after a PLC, we consider PPCK as a suitable construct to examine their knowledge. Furthermore, we were interested in the development of a shared, collective knowledge base of the O\&O teachers as a group. During the PLC, the teachers constructed several products together. We already know from other studies that such activities can lead to enhanced teacher PCK (Coenders et al. 2010), and can also contribute to the development of a shared, collective knowledge base (Gess-Newsome 2015).

To examine individual teachers' pPCK, we adopted four domains of PCK as described by Magnusson et al. (1999): teacher knowledge about goals and objectives (M1); teacher knowledge about students (M2); teacher knowledge about instructional strategies (M3); and teacher knowledge about assessment (M4). Domain M1 includes teachers' knowledge of the goals and objectives for students and why it is important that students reach these 
learning goals (Barendsen and Henze 2017; Magnusson et al. 1999). Domain M2 includes knowledge of student requirements for learning specific science concepts, and areas of science that students find difficult (Magnusson et al. 1999). Domain M3 includes knowledge of teaching procedures and methods to teach a certain concept. Magnusson et al. (1999) describe this knowledge to be subject-specific or topic-specific, however in our case, the knowledge about instructional strategies related to the connection between research and design is rather domain-specific to STEM or practice-specific. Domain M4 includes knowledge of the dimensions that are important to assess, and knowledge of the methods by which that learning can be assessed (Magnusson et al. 1999), and why these methods are suitable.

Another, overarching domain is that of orientations and beliefs, which shapes other components of PCK and thereby influences teacher PCK and teacher practice (Magnusson et al. 1999). Beliefs are not a well-defined construct (Jones and Legon 2014), and scholars have adopted contrasting representations of beliefs and knowledge (Veal 2004); knowledge has been described as a component of beliefs (Rokeach 1968), and beliefs have been described as a special form of personal, tacit knowledge (Kagan 1990). The difference between knowledge and beliefs is hard to describe, but in general, beliefs are regarded as less linked to cognition (as knowledge is), but more to affect and evaluation (Jones and Legon 2014; Pajares 1992). Beliefs have also been defined as "understandings, premises or propositions about the world that are felt to be true" (Richardson 1996, p. 103). These premises can arise from a number of sources: believing an authority, deductive logic, the experience of the senses, the emotion of feeling that something is true or right, rational intuition, and personal use of the scientific method (Lewis 1990). Beliefs can differ in intensity and are linked to one another; the more a certain belief is connected to and influences other beliefs, the more central this belief (Rokeach 1968). Beliefs strongly affect behavior (Pajares 1992): beliefs influence for example how teachers make decisions for implementing instructional strategies (Veal 2004) and which knowledge teachers choose to draw upon (Leinhardt and Greeno 1986). Beliefs and knowledge are thus tightly interwoven (Gess-Newsome 1999; Pajares 1992), and it is highly likely that upon eliciting teacher knowledge like pPCK, we will also get insight in teacher's beliefs about the connection between research and design.

\section{Method}

To examine teacher knowledge development on connecting research and design, we did a qualitative, explorative, multi-case study, in which we made in-depth descriptions of the personal PCK development of 6 O\&O teachers, and in-depth descriptions of the products that the teachers developed collectively during the PLC.

\section{Context}

The context of this study is the Dutch subject O\&O (Dutch abbreviation for 'Research and Design'), which was introduced in 2004 and is now taught at 98 certified, so called 'Technasium' secondary schools in The Netherlands from 7th to 12th Grade. O\&O is a project-based, elective subject where students conduct authentic research and design projects based on real world science or STEM related problems from companies and clients in the schools' area. In an O\&O project for example, students write a research report with advices to the local client for the optimization of an algae reactor. Another example is that 
of a project in which students design a game or an app for a local petting zoo, considering its target group. One of the main goals of the subject O\&O is to make students familiar with research and design practices in the professional world. However, projects in O\&O are labelled as a research project or as a design project in the project database founded by the Technasium foundation. In reality, many O\&O projects include both research and design activities because they are based on authentic problems, but whether this relation between research and design is clear and visible to both teachers and students, is uncertain.

\section{Participants}

Seven O\&O teachers participated in the PLC, of whom six completed the study (see Table 1). The teachers that were approached were in schools that had already showed interest in previous research about the subject $\mathrm{O} \& \mathrm{O}$ by the authors. The teachers were approached individually by email, in which information about the PLC meetings and about the study were given. Some of the approached teachers recommended the PLC to colleagues, of which some also enrolled for the PLC and the corresponding study. All teacher names used in this study are pseudonyms, to ensure anonymity.

\section{The professional learning community}

The main aims of the PLC were to increase teacher knowledge about the ways in which research and design can be connected, and how they can communicate this connection to their students through instructional strategies (for all intended learning outcomes of the PLC, see "Appendix"). We wanted teachers to learn that research and design can be connected in many different ways (for example: doing research is necessary for design, and after doing research, one can make recommendations for a design to apply the results), and how to facilitate this connection in their classrooms (for example by developing short instructional strategies, or adapting existing projects). So, the focus of the PLC was mainly within domains M1 and M3 of Magnusson et al. (1999): knowledge about goals and objectives and knowledge about instructional strategies related to the connection between research and design. Four PLC meetings of $3 \mathrm{~h}$ each took place in October 2016, November 2016, January 2017 and February 2017. All PLC meetings were facilitated by the first author of this study, to whom we will refer as $\mathrm{F}$ in tables and quotations. Below, we will provide rich descriptions of the content of each PLC meeting.

In the first PLC meeting, the facilitator presented the outline of the PLC. A big part of the first meeting was dedicated to an expert lecture about research and design that was given by an experienced $\mathrm{O} \& \mathrm{O}$ teacher educator (to whom we will refer as TE in tables and quotations) from a nearby university. Teachers discussed their views on research and design, and the connectedness of the two. As the first lecture was slightly more design focused, a second short lecture on specifying research questions was given by the facilitator of the PLC (F).

In the second PLC meeting, consensus on the common goals of the PLC was reached: learning about the connection between research and design (and corresponding instructional strategies), learning about research and design separately, and opportunities to connect with the other teachers in the PLC for professional gain. Then, teachers were asked to jointly construct a Content Representation (CoRe): 'an overview of how teachers approach the teaching of the whole of a topic and the reasons for that approach-what content is taught and how and why' (Mulhall et al. 2003, p. 6). First, the teachers formulated an 


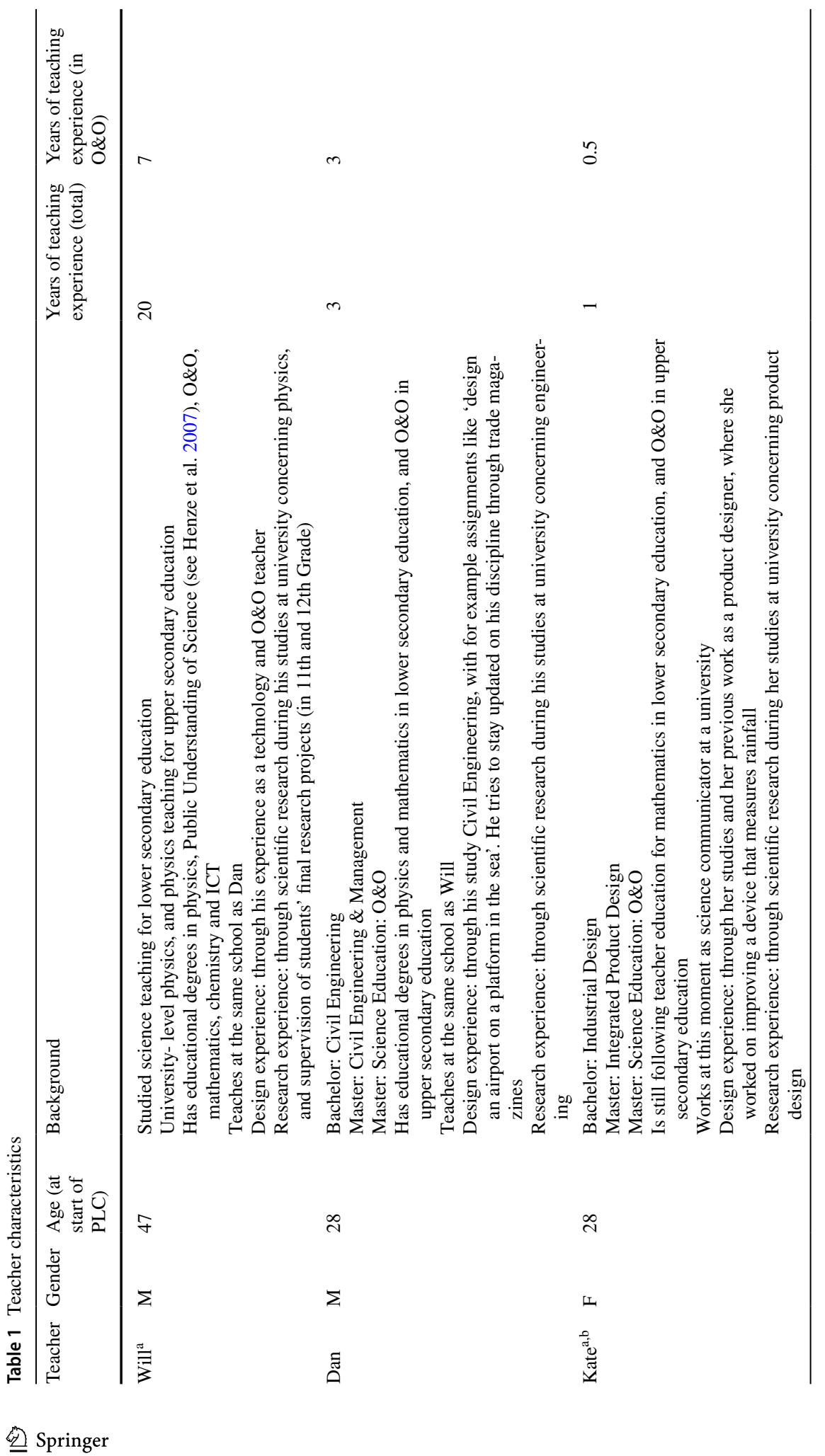




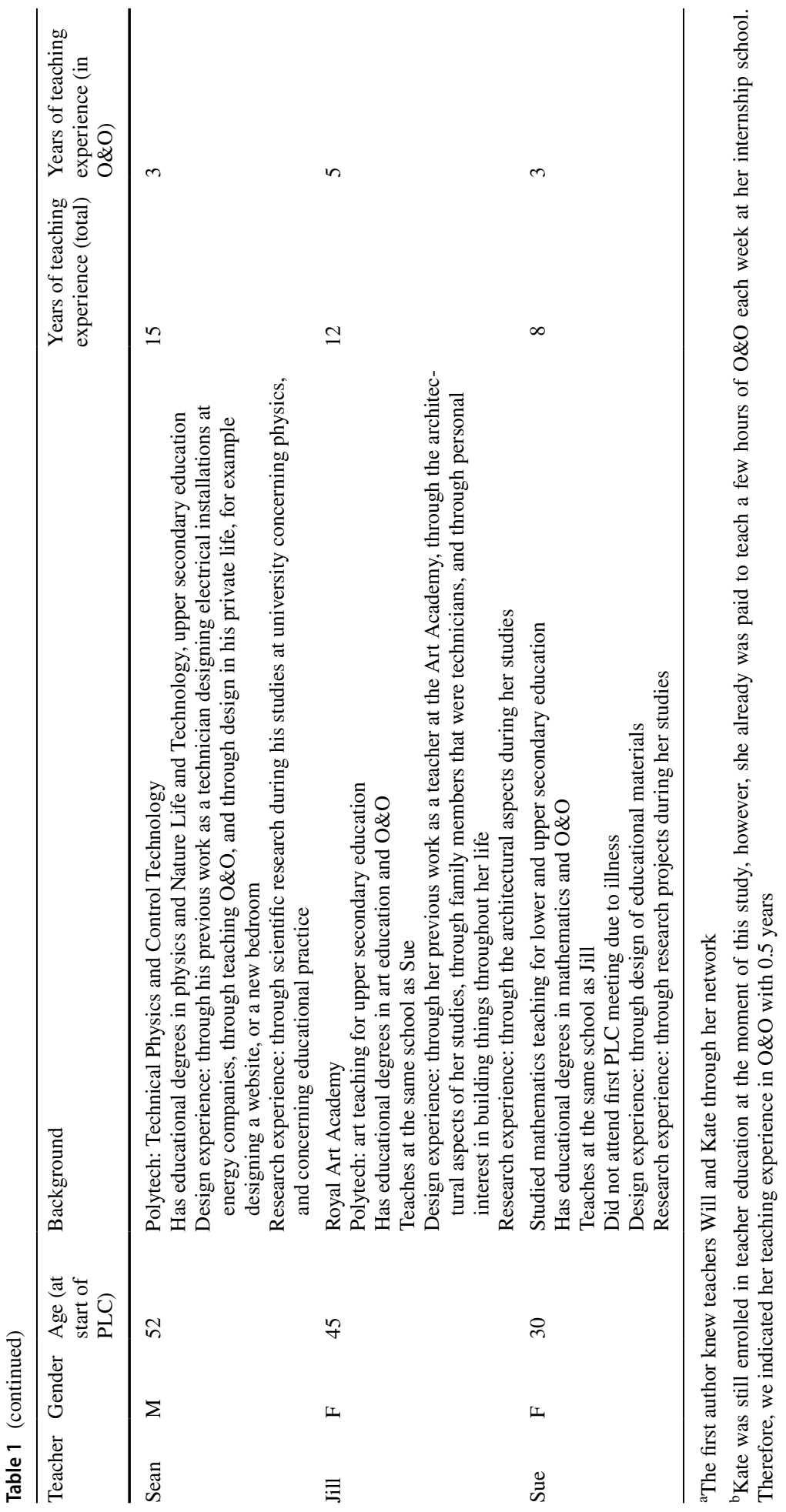


overarching statement (a so-called 'big idea'): "Within a research and design project, you have to be able to choose certain methods and justify them". Then, they discussed the several aspects of this big idea (related to the four domains of Magnusson et al. 1999): what were the learning goals attached to this idea, why was it important that students knew about this, how would they give instruction to students regarding this big idea, etc. They produced a CoRe table as a group in a discussion structured by the facilitator. Teachers were also asked to develop short instructional strategies (so-called plug-ins) in groups of 2-3 after a brainstorm session. Plug-ins are short, low cost instructional strategies that have ready-made material and can be implemented in any O\&O project without too much preparation time. The intended learning outcomes of the plug-ins developed in this PLC were to make the connection between research and design explicit for students. After presenting their plug-ins to each other, the facilitator encouraged the teachers to try out the plug-ins in their classes before the next meeting.

In the third meeting, teachers were asked to share their experiences with testing the plug-ins. As teachers participated in the PLC voluntarily and the testing of the plug-ins in their own classrooms was not mandatory, not all teachers had tested their plug-ins. In that case, they were asked to describe an experience in which research and design were connected in a successful way in their class. Then, the teachers adapted the plug-ins based on each others' comments. The teachers were also asked to adapt an example O\&O project in pairs according to the outcomes of the CoRe they constructed during the previous meeting. They formulated principles for redesigning the projects to include a connection between research and design, for example: "The different parts of the project have to match up with different research and design methods". After $1 \mathrm{~h}$, teachers presented the adaptations they made to each other.

In the fourth and last meeting, the facilitator started with a short recap of the previous meetings and asked teachers to evaluate the plug-ins one last time after some teachers had tried them. Then, teachers worked on adapting O\&O projects of their own schools, so that these included clear links between research and design components. Finally, teachers discussed tools they would like to see developed in the future, and evaluated the PLC as a whole.

\section{Data collection}

To elicit teachers' pPCK and beliefs regarding connecting research and design in the classroom (research question 1), semi-structured interviews were conducted by $\mathrm{F}$ before the first meeting and after the last meeting of the PLC. The questions were loosely based on Content Representations (Loughran et al. 2006), and strongly on the PCK model of Magnusson et al. (1999), including the four domains: (M1) knowledge of goals and objectives; (M2) knowledge of students; (M3) knowledge of instructional strategies; (M4) knowledge of assessment. As teachers' knowledge is informed by their belief systems (Gess-Newsome 1999), we aimed to elicit teachers' beliefs from these interviews as well. The interviews were audio recorded and transcribed in verbatim. The PLC meetings were recorded on audio and video, and group work during the meetings was recorded on audio. Of all teachers, active consent was obtained. Ethical approval was obtained from the Ethics Committee at the Leiden University Graduate School of Teaching.

To examine how the teachers collectively gave meaning to the connection between research and design, we examined the products that teachers co-constructed during the PLC. It has been shown that developing educational products together enhances shared 
teacher knowledge (Coenders et al. 2010). In our case, these were the plug-ins (short, instructional strategies) that teachers developed. We collected the plug-in instruction manuals that the teachers wrote, and asked them to reflect on the plug-ins collectively during the PLC, and individually during the post-PLC interviews. Also, the teachers constructed a CoRe together; a representation of how a community of teachers thinks about the knowledge needed to teach a particular topic (Gess-Newsome 2015). We summarized the outcomes of the CoRe to elicit salient issues within our teacher group.

\section{Analysis}

To elicit the individual teachers' pPCK and beliefs (research question 1), the pre-PLC and post-PLC interview transcripts were used as the main data source. The recordings of the PLC were used as supporting data. The analysis of the interview transcripts was based on the four domains of the PCK model of Magnusson et al. (1999). First, the interview transcripts were read thoroughly several times. The first and second author analyzed the interviews with a conventional content analysis approach (Hsieh and Shannon 2005) guided by the four domains of Magnusson in Atlas.ti version 7.5.6. A teacher's answer to each interview question or follow up question was coded as a separate segment, unless the answer on the follow up question (or follow up remark) was a clear continuation of the previous statement, or if the additional information was needed in order to understand what the teacher exactly meant by his/her previous statement. After coding all segments, we removed codes that represented teachers' statements about the subject O\&O in general, as we wanted to explicitly explore their PCK about the connection between research and design. We then revised all codes, and made an analysis of themes (Creswell 2007) by only coding explicit statements on the connection between research and design, statements on research and design when they were mentioned in combination with each other, separate statements on research, and separate statements on design. This resulted in a list of codes for each individual teacher. After revising these lists, small adaptations to some codes were made to make them more comprehensible. Consensus between the first and second author was reached on the codes that remained.

We grouped all single codes under meaningful bigger categories within the domains of Magnusson et al. (1999). We constructed in-depth, explorative descriptions for all teacher cases, to characterize his/her knowledge development by comparing codes from the pre-PLC and post-PLC interviews, because each teacher case was different and unique. We selected the richest and most meaningful quotes from each teacher, regarding salient issues in their knowledge development, or central beliefs to which their development was related. We also compared teachers' PCK to the intended learning outcomes of the PLC (see "Appendix").

The collective knowledge construction of the teachers (research question 2) was informed by the Content Representation (Mulhall et al. 2003) they constructed together in the second PLC meeting. We looked for salient issues in the table of outcomes they developed during their discussion on the several CoRe elements. We also analyzed the two main plug-ins the teachers designed in groups, and teachers' reflections on these instruments during the PLC and during their individual post-PLC interviews to characterize these instructional strategies. Out of the in-depth descriptions of the plug-ins, we could extract information about the types of instructional strategy that the teachers as a group preferred and about which learning goals they had attributed to these activities. 


\section{Results}

The results are structured according to the order of the research questions. Data on the first research question about teachers' pPCK and beliefs is structured according to each teacher case. Data on the second research question is structured according to the three products that teachers constructed (the CoRe and two plug-ins).

\section{Teachers' personal PCK and beliefs development: pre and post PLC}

\section{Will}

In domain M1, knowledge about goals and objectives, Will's starting position was that he could, after probes by the interviewer, already mention different learning goals for students about the connection between research and design which were also intended learning outcomes of the PLC. In the post-PLC interview, Will actually mentioned less of the different M1 learning goals when compared to his starting position. Instead, he seemed to focus on the learning goals related to his central belief that it is a prerequisite that students see the utility of research within design. This was a salient issue in his reasoning after the PLC in domains M1 ('students need to know that doing research is needed to conduct a design'), M2 ('students see the relevance of a project through using research within their design') and M3 ('I stimulate students in the importance of doing orientation research'). He indicated that the PLC enhanced his ideas about the importance of this issue:

I think that, it was in my head before the PLC: 'You cannot do one without the other [research or design], it is just connected'. That was implicit at first, but I think I am more explicit now, I indicate more clearly: 'Why do we do research for our design? What is the importance of doing this orientation research?'.

Making the connection between research and design explicit to students (M3: knowledge of instructional strategies) was one of the intended learning outcomes of the PLC. In the pre-PLC interview, Will struggled whether or not he should do this. When asked about which instructional strategies he wanted to use, he answered:

I do not really have an answer to that... I think it [the connection] is already hidden within the project description itself.

In his post-PLC interview, Will made more sophisticated statements about strategies for instruction, using more specific wording:

I would indicate in the project description, within the material we offer students, indicate more clearly and explicitly whether a part within the project is about doing research, or whether a part within the project is about designing, for example research, research, design, really indicate per part: 'This is what you are doing now'.

\section{Dan}

Dan, like Will, could already in his pre-PLC interview mention different learning goals for students about the connection between research and design in domain M1, knowledge about goals and objectives. After the PLC, Dan mentioned less different intended learning 
outcomes related to learning goals for students (M1), but he did mention different goals than he did in his pre-PLC interview. This indicates that he adopted new knowledge of domain M1 during the PLC: for example that students should know that looking up information is not the same as doing research, a topic that was discussed during the first meeting.

In his pre-PLC interview, a central belief of Dan was that students' in general disfavor doing research. Among his most mentioned codes in M2 (knowledge about students) were 'students find doing research boring and stupid' and 'students do not see the need of doing research within design'. He did not make specific statements about students in relation to the connection between research and design yet. In his post-PLC interview, Dan made relatively less negative statements about students, and he mainly mentioned difficulties students had when connecting research and design, for example when students do not test or improve their design:

At this moment, it [the connection] is not obvious for the students yet... They like designing, they do the design cycle just once. They are really rigid, to my surprise, they say very quickly: 'This is our design'. And then I try to change their minds, or let them think about: 'But why? Can't it be better?' But students are very rigid: 'This is our design, can we build it now?

In domain M3, knowledge about instructional strategies, it is surprising that Dan, in his pre-PLC interview, mentioned that adapting the project description could be an approach to make clear the connection between research and design, while after the PLC, which also had this principle as an intended learning outcome, Dan did not mention this anymore. He seemed to focus more on his idea of addressing the connection within workshops, providing students with open projects, and on evaluating the plug-ins the teachers made in the PLC, although he had not used one of the plug-ins yet. He also mentioned again that he wanted to show students that doing research is not the same as looking up information, which was consistent with his statements in domain M1.

\section{Kate}

Post-PLC, Kate mentioned that research and design request different skills, and that when research is used within design, it becomes less of an art project, which means she has adapted some of the intended learning outcomes of the PLC (see "Appendix"), although not excessively. At the start of the PLC, Kate said she wanted students to recognize the connection between research and design (which relates to student knowledge), however after the PLC, she stated she found it more important for students to be able to actively apply the connection within their projects (which relates to student skills):

... but if you think: Is it really important that they [students] know all the descriptions of the concepts and get them right, or is it more important that they can carry out the process in the right way? Then I think the latter is much more important.

In both her pre-PLC and post-PLC interview, Kate showed the central belief that all ideas, even misconceptions of students should be able to exist, in order for them to get the chance to discover for themselves whether a research or design idea works or not. In her post-PLC interview she mentioned that students are used to pleasing the teacher and doing as he/she says, but that it is an eye-opener for them if they realize they can choose any approach to a project, as there is not one correct answer: 
... they [students] were asking me what the best answer was. And then I said I was really happy with their discussion, because that made them real designers. Because, if they choose to go in one direction for a certain reason, and if they can explain this reason to the client, or they can go in another direction, that's both fine, as long as they explain their choices. So they had to decide on the answer, not me. And this was an eye-opener for them I think.

In her pre-PLC interview, Kate mentioned a lot of strategies she could use as a teacher to support students' design projects. This variety of strategies were probably implied by her background as a designer and science communicator, she mentioned. In her post-PLC interview, Kate mentioned relatively less different instructional strategies when compared to her starting interview, however, she talked a lot about one instructional strategy she had recently used to make user research prior to a design project more appealing to students. She let her students sort questionnaires within different typologies of users, instead of letting them analyze the questionnaires quantitatively on the computer. She found this a successful experience in connecting research to a design project, because her students actually used research to inform their design after this exercise.

\section{Sean}

In his starting interview Sean mentioned less different goals and objectives (M1) than after the PLC, indicating he had developed his knowledge and adopted some of the intended learning outcomes of the PLC. For example, he mentioned that research and testing is important for design, otherwise it becomes art (one of the intended learning outcomes as stated in the "Appendix"). Also, after the PLC, Sean was more convinced of the importance of letting students test their design:

And persuade students they have to do something. That they make a design, but test it and certainly need a second and third design, at the end of the project, it is important to mention that. They are often slow, and at the end of the project they are stressed and don't have time to test anymore. So I say: 'Just go make something and we will adapt it, just do it'. I am guiding them more directly, so to say. Before I think we mentioned it: 'hey, shouldn't you test this'. But now I think: if you did not test [your design], then it will certainly not be sufficient, so I am more coercive in what they have to do.

This quotation also relates to domain M3, knowledge of instructional strategies, as Sean also pointed out he wants to stimulate students to test their design. Sean appeared to be ambivalent at the start of the PLC on whether or not to make the connection between research and design explicit to students. In the pre-PLC interview, he gave mixed answers about the importance of making explicit this connection or not. In his post-PLC interview, Sean said that he would make the connection explicit, but rather communicate this to students during group work than in a plenary fashion:

Naming it [the connection] constantly in conversations. [talking about connection] Plenary, it does not make much sense I think, in the sense of talking about it at the beginning of the lesson, but rather in short workshops...

Sean also tried one of the plug-ins he designed with his students, contrary to Will, Dan and Kate. He mentioned some restrictions however, which we will discuss in the next paragraph when we analyze the plug-ins the teachers made. Sean clearly had a 
desire to implement practical instructional approaches in his lessons. Perhaps this motivation stemmed from his background as a technician.

A central belief of Sean, in both his pre and post interview, is that he found justification of student statements really important. He wanted students to justify their choices and claims within the research and design projects. It became obvious that this was a really important issue for him.

\section{Jill}

At the start of the PLC, Jill mentioned little variety of goals and objectives regarding the connection between research and design (M1). A salient issue in all knowledge domains in her pre-PLC interview was a role division strategy, in which students fulfilled and switched between certain roles within an O\&O project: the planner, the researcher, the designer, and the chair. It became clear that she believed this was one of the best ways to let students see the connection between research and design. Jill also stated in her pre-PLC interview that she would not make the connection between research and design explicit to her students, because she believed her students already saw this connection:

I don't know, making it explicit, it is so logical, you don't build a house without doing research on materials, so in any case, orientation knowledge is necessary for a design. I think that when you ask a student, they would say: 'That's logical, isn't it?'.

After Jill's post-PLC interview, she had formulated more and clearer learning goals she wanted her students to achieve, for example, she wanted them to see there that the interaction between research and design allows them to make a good product, and she wanted students to think about differences between research and design. There was more variation in her knowledge of goals and objectives (M1) compared to her starting position, and she did not mention her role division method as much as before. Contrary to her opinion in the starting interview, she stated after the PLC that the connection between research and design is something that should be named:

What was striking to me, and it is just true, you have to make it [the connection] visible for them [the students], so putting up posters in the classroom, denominating it real often, show pictures. Like you made that link clear to us: 'Where are you in the cycle? Where does the connection lie?' Then you can name it and put your finger on it, and those considerations you do make in your head, but it is good to always make it visible.

In M3, knowledge about instructional strategies, Jill showed a lot of initiative by having tried one of the designed plug-ins in her lesson, and by having designed another instructional method by herself. She elaborately talked about the latter, a method called 'mythbusters' (referring to the well-known television program), in which she let students check a statement given to them on a card. Students got a box of materials with which they could design an experiment, and test whether this statement could be true. She stated that students were enthusiastic:

The students were instantly enthusiastic about being allowed to do research, immediately getting to work with the materials, to see if the facts were true.

\section{Sue}

Sue missed the first PLC meeting due to illness, so she missed information about the PLC's intended learning outcomes in M1, knowledge of goals and objectives, which were mainly 
treated in the first meeting. We saw indeed that post-PLC, Sue mainly made general statements about M1, like 'doing research (gaining knowledge) is part of, and necessary for, designing'. However, for some other teachers, this is also the case, as after the PLC they have specific learning goals in mind (for example Will). Before the PLC, Sue stated that students have to recognize the connection between research and design. However, after the PLC, she stated she was in doubt about this learning goal for students she mentioned at the start. This is illustrated in this quotation from her post-PLC interview:

F: "Is it important that students know something about the connection?"

Sue: "I'm in doubt."

F: "What is it that makes you doubt this?"

Sue: "If it just feels right for them. It's so logical that you switch between [research and design]. And if it feels logical for them and they just understand that before they are going to do something, they need to know something first. Then to me it doesn't matter whether they put it under the term research or design. If they just, I'm in doubt."

F: "So if they are working nicely in the process, so to say?"

Sue: "Yes. They have to know what they are doing, and that you need the one for the other, but if that one's name is either research or design [is not important]."

It seems that after the PLC, Sue believed it is more important that students are able to carry out the process of connecting research and design, rather than students being able to name this connection. A similar statement was made by Kate in her post-PLC interview. At the start of the PLC, Sue's most mentioned code in M1 was 'students must recognize the connection between research and design', whereas after the PLC, Sue mentioned the statement that 'the connection must feel logical for students' more.

In domain M3, knowledge of instructional strategies, Sue had some ideas about methods in her pre-PLC interview, like dividing students into research and design specialists, or letting students sort cards with all the parts of the project under the headings 'research' and 'design'. One of the plug-ins loosely resembled the latter, and Sue also tried this plug-in with her students. Like Jill, Sue also thought in her post-PLC interview that students found the connection between research and design logical, and like Sean she wanted to make the connection explicit during group work instead of plenary. In her pre and post interview it was Sue's belief that it was important to structure the projects clearly for her students. In her post-PLC interview, she added that projects also should not always follow the same structure, in order for students not to get bored.

\section{Teachers' collective meaning making to the connection between research and design}

\section{The content representation}

During the construction of the CoRe, the teachers discussed which 'big ideas' about connecting research and design were important, what the related learning goals were for students and how to implement these in a project. Teachers discussed several big ideas and voted for the most important ones: 'during research and design, you have to justify your choices', and 'research should be made "sexy" by connecting it to design'. Eventually, the main big idea was constructed on which we based the CoRe: 'Within a project, you must be able to choose research methods and design methods, and justify them'. 
It is remarkable that 'choosing the right research and design method is important' was a big idea that only one individual teacher voted for. It was during the group discussion prior to choosing the main big idea, that the ideas 'you have to justify your choices' and 'choosing suitable research and design methods is important' became merged. This showed that the O\&O teachers collectively assigned importance to choosing the right methods, even when individual teachers did not mention this extensively during their pPCK interviews. The teachers even mentioned that they had a need for a canonical depository with a range of research and design methods they could consult for their projects. During the discussion, the teachers often switched from one big idea to another, as they saw everything as related to each other. This showed that they had some difficulty to break down the broad, practiceoriented issue of connecting research and design into smaller units or learning goals.

Cross-case analyses showed that several learning goals were adopted by all teachers after the PLC, for example 'students should know that doing research is needed for their design', 'we should make the connection between research and design explicit (during group work)' and 'reasons why students need to be able to connect research and design'. Also, after the PLC, more teachers mentioned that 'students need to justify their choicesa central belief of Sean, who might have transferred this to others. These collectively agreed upon learning goals are an indication of a shared knowledge base. All teachers also agreed that the group atmosphere in the PLC was very positive.

\section{The plug-ins that teachers developed}

Teachers developed their own short instructional strategies, or plug-ins, in teams, and reflected upon them collectively during the PLC and individually during the post-PLC interview. In the next two paragraphs, we will discuss and describe two of the designed plug-ins, as these were the most discussed by the group and tested by several teachers, and matched best with the PLC's goal to connect research and design.

During the second PLC meeting, teachers Jill and Sue worked together on designing the plug-in 'Flip over signs'. They designed a sign that students can place on their desk and flip over: one side of the sign reads 'research', the other one 'design'. The sign reflects what the students are doing. While working on their project, students are supposed to flip over the sign according to whether what they think they are doing is research or design related. The teacher can initiate a discussion about the signs. The intended learning outcomes of this plug-in are to make students aware that they switch between research and design activities during the same project, and to engage students in a discussion with the teacher about the connectedness of research and design. The other teachers were positive about the idea of the flip-over signs:

Sean: "Because it's so simple, children have to agree upon what they are going to do.

Or divide them, within groups you can do something else, but you have to talk about

it. So if there's a sign you have to place, you have to do something with it".

Kate: "Groups can indicate whether they are doing things more design related or research related. I think that is a confirmation or awareness: research and design are not so black and white, it dissolves into each other more than I thought before".

Dan stated that he was sceptical, and that the plug-in did not appeal to him, although he admitted that it was probably because he did not walk by the teams of students so often, which was a requirement for this plug-in in order to start discussions about the flip-over signs.

Kate, Sean and Dan designed the plug-in 'Explain it!'. This plugin was a competitive game in which two teams of students try to convince each other that they made the best 
thinking steps within their project, and in which students can give each other feedback. The game consists of cards with different statements related to the project, for example: "Explain how you have used orientation research for your design project". The intended learning outcome of this plug-in is to engage students in a discussion on the justification of the research and design choices they made within their projects. Also, the set-up of having a discussion as a game also invites students to learn from each other's' successes and mistakes. The teachers were quite enthusiastic about this plug in because of the element of competition, although there were some practical restrictions.

Sean actually tried this plug-in with his students:

The plug-in we made ourselves, with the cards where children could convince each other why they were really good at the research and design parts of the project. That is a nice plug-in, but there has to be enough time. There are few moments in which that [plug-in] is efficient. If they have not done anything yet, it had no use, and if they are done [with the project], then it's too late. So the timeframe in which to implement this is narrow.

When the O\&O teachers designed instructional strategies together during the PLC, this could lead to the development of collective knowledge. The plug-ins show for example that the teachers still thought of research and design as more-or-less separate entities, as the flip-over signs read 'research' or 'design', and 'Explain it!' contained not only questions about the connection, but also questions aimed at research only or design only. For this reason, Dan even stated that he was sceptical whether the plug-ins even established the connection between research and design. However, both plug-ins were designed to start a conversation with or among students: letting students think and verbally reason about the possible link between research and design was clearly a shared learning goal of the O\&O teachers. The importance to justify research and design choices, one of the components of the big idea that teachers chose for the CoRe, also featured in the plug-in 'Explain it!'. This game was primarily aimed at justifying research and/or design choices.

\section{Discussion}

The discussion is structured according to the order of the research questions, which are stated in the last paragraph of the theoretical framework.

\section{Teachers' personal PCK and beliefs development}

The results of this study showed that the pPCK of each teacher was different and developed in a different way. Some teachers broadened their knowledge about learning goals regarding the connection between research and design, however some teachers merely shifted to other ideas or narrowed their existing knowledge further. Thus, teachers did not cluster together in certain typologies, like those found in other studies on PCK (Henze et al. 2008). Research that uses individual teachers as the unit of analysis confirms that teacher learning can be unpredictable, and that some teachers change more than others during professional development (Borko 2004; Franke et al. 2001). Teachers from the same school (e.g. Jill and Sue), or with similar educational backgrounds (e.g. Kate and Dan), had different pPCK. This illustrates that all teachers had different experiences and qualifications regarding research and design, indicating they all had different independent 
knowledge of research and design at the start of the PLC. Combined with their different personal beliefs, this could have led to the variety in knowledge development. These findings also contribute to the notion of ambiguity in research and design pedagogy and epistemology. In follow-up research, it would be interesting to examine the epistemology of (the connection between) research and design along with teachers and other education specialists. It is likely that the teachers' attitudes, beliefs and personal, educational or professional experiences acted as amplifiers or filters on their knowledge development, thus contributing to teachers' varied pPCK (Gess-Newsome 2015). Every teacher viewed the pedagogy of connecting research and design differently and acted differently because of the variety in knowledge and beliefs-otherwise we would have found typologies. However, the teachers' thinking and verbal reasoning about the pedagogy of the connection between research and design did evolve during the PLC, as they made more explicit statements about this topic after the PLC when compared to their starting position.

Teachers' pPCK could have been strengthened further by repeatedly testing instructional strategies aimed at connecting research and design, like the plug-ins they developed, and reflecting on these actions in the classroom practice (Clarke and Hollingsworth 2002). However, the teachers in our sample did not extensively apply the plug-ins 'Flip-over signs' and 'Explain it!' in their classrooms during our study (which was strongly advised, but not mandatory). Possibly, this was related to a lack of skills for implementing these new strategies in the classroom (Gess-Newsome 2015), or to the issue that teachers' knowledge about teaching the connection between research and design was not strong enough yet to provoke significant changes in their behavior in practice (Barendsen and Henze 2017; Park and Chen 2012). Literature shows that some elements of teachers' knowledge and practice are more easily changed than others, and changing instructional strategies is one of the harder elements to change (Borko 2004; Franke et al. 2001). It is also possible that some of the teachers in our sample applied the developed plug-ins in their classrooms in the period after the PLC, thus enhancing their pPCK development outside the scope of this study.

The teachers showed explicit and different beliefs during their interviews on pPCK. For example, a central belief of Sean was that students needed to justify their choices, and a central belief of Will was that students should first know how to do orientation research before they design. One of the central beliefs of Jill was that students should learn about citizenship, a goal that was not mentioned by the other teachers; perhaps this belief was implied by her background as an arts teacher. These central beliefs about some important learning goals were not changed after the PLC, whereas teachers' beliefs about the importance of teaching the connection between research and design did change (for example the belief that students should be able to apply their knowledge about connecting research and design, instead of merely understand its presence). Their central beliefs likely influenced teacher knowledge development during the PLC (Leinhardt and Greeno 1986). For example, Will shows a narrowing of his knowledge in his post-PLC interview. His central belief was that it was a prerequisite to understanding the connection between research and design, that students saw the necessity of orientation research before conducting a design. Attending the PLC might have enhanced this central belief for Will.

\section{Teachers' collective meaning making to the connection between research and design}

Although each individual teacher had different knowledge and beliefs, the results of this study also showed that teachers built a collective knowledge base during the PLC. During the 
construction of the CoRe, the teachers as a group adopted the idea of the importance of justifying research and design choices, and the importance of choosing suitable research and design methods. We saw that during the discussion on the CoRe, the teachers had difficulty to choose and stick to one particular big idea, as they saw all big ideas as connected to each other. Previous attempts to use the CoRe tool with D\&T teachers provided similar results: in comparison to science educators, D\&T teachers found it challenging to identify specific big ideas for lessons in D\&T (Williams et al. 2012). Possibly this is due to the fact that there are no canonical schemas that are familiar to all D\&T teachers, or because D\&T, and in our case, research combined with design, do not have well-established epistemologies (Doyle et al. 2018).

After the PLC, all teachers understood the importance of the connection between research and design, and certain ways of connecting research and design were more appealing to the teachers as a group than others. For example, the need to do orientation research before conducting a design was mentioned multiple times by all participating teachers during the PLC, and in their post-PLC interviews. The need to justify choices within the project was also mentioned by more teachers in their post-PLC interviews, and during the development of the CoRe. During the course of the PLC, these topics were salient issues in the teacher conversations, and featured in the plug-ins. For example, 'Explain it!', was a game aimed at justifying research and/ or design choices. The development of the plug-ins indicated that teachers wanted students to be engaged in a dialogue with the research or design process or product through justification and evaluation of choices. A reason for this could be that these topics were linked to some of the teachers' central beliefs: for example, the central belief of Sean, that students should justify choices, or the central belief of Will, that orientation research is critical to the further course of a design project. Through conversation and sharing, the central beliefs and pPCK of individual teachers could very well have contributed to the collective knowledge base of the teacher group. According to the new Refined Consensus Model on PCK, this could be seen as the development of a form of collective PCK: an amalgam of different educators' contributions, shaped through knowledge exchange during discussions and the collective development of instructional strategies, resulting in a shared knowledge base around a particular topic (Carlson and Daehler 2019).

\section{Limitations and implications}

Teachers' PCK about connecting research and design was quite tacit at the beginning of the PLC. After the PLC, teachers made more and clearer statements about the connection between research and design, but these were also not yet very sophisticated. The timespan of just four meetings is quite a short time to expect a large impact on teacher PCK development (Supovitz and Turner 2000), especially since this was the first time the teachers in this study explicitly thought and talked about connecting research and design. However, other research has shown that more short-term interventions with tightly focused topics can actually have a moderate positive effect on teacher knowledge development (Rollnick et al. 2017). In that sense, the PLC in this study was successful in letting teachers' think explicitly about the specific practice of the connection between research and design for the first time and framing their minds towards a more integrated practice of research and design. We recommend providing additional support in the form of PLC meetings/activities to STEM and D\&T teachers who are expected to teach across different domains and activities, as teachers generally require additional education for linking the different STEM domains (Shernoff et al. 2017; Stohlmann et al. 2012). 
In this study, teachers' knowledge, beliefs and backgrounds were all very diverse. Should we have included more teachers in our sample, it is likely that they would have again had different beliefs and different ways to develop their knowledge. To know whether a certain (personal, educational or professional) background leads to a certain pattern in teachers' knowledge development, more teacher groups with similar backgrounds should be included in follow-up research. As teacher's personal science backgrounds, peers and personal traits influence how they put their beliefs in practice (Veal 2004), these follow-up studies should also look into the interaction between teachers' backgrounds, beliefs and knowledge, to truly understand the reality of classroom practice (Doyle et al. 2018). This also implies that schools, wishing to establish STEM and D\&T teacher teams, should pay attention to, and make explicit the different beliefs of teachers. Further research should look into how these groups of teachers can specify their central beliefs and learning goals, in order for them to be able to develop their knowledge and their lessons together.

\section{Conclusion}

In conclusion, despite the short time span of the PLC, teachers did become more aware of the connection between research and design in practice as well as in their classroom subject O\&O. Teachers developed their own knowledge (pPCK), but also contributed to the shared knowledge of the group. The knowledge development of the teachers can be attributed to the discussions, lectures and activities provided during the PLC meetings, but also to the one-on-one interviews with the first author, which were in-depth conversations about their individual learning goals and classroom practices. Teacher Will even stated:

The funny thing is, the most valuable for me is perhaps this conversation. Just because you can sort out your thoughts.

All teachers in our group reported very positively on the group atmosphere, and strong PLCs based on trust and good communication can foster teacher learning and instructional improvement (Borko 2004).

This study shows that a professional learning community in which teachers with varying backgrounds construct knowledge and instructional strategies together, as well as individual in-depth conversations with a facilitator aimed at teachers' PCK development, are powerful methods to enhance personal and collective PCK. These are promising outcomes in the light of shaping professional development activities for STEM and D\&T teachers. To date, very little is known about how to connect research and design activities to each other in D\&T and integrated STEM education. Connecting research and design in the classroom has the potential of providing students with a holistic and realistic view on current professional STEM fields, while studies on teacher knowledge and strategies about the connection of research and design activities are scarce. Our study provides valuable insights in teacher knowledge development about this practice.

Acknowledgements We would like to thank the O\&O teachers Will, Dan, Sean, Kate, Jill and Sue for participating in our PLC and study. Our thanks also go to Snjezana de Haan-Topolscak, for providing a lecture during the PLC as an O\&O teacher educator. We are grateful to dr. Dineke Tigelaar, who provided feedback on the later versions of the manuscript. 


\section{Compliance with ethical standards}

Conflict of interest The authors declare that they have no conflict of interest.

Informed consent Of all participating teachers, active informed consent was obtained.

Ethical approval Ethical approval was obtained from the Ethics Committee at the Leiden University Graduate School of Teaching.

Open Access This article is distributed under the terms of the Creative Commons Attribution 4.0 International License (http://creativecommons.org/licenses/by/4.0/), which permits unrestricted use, distribution, and reproduction in any medium, provided you give appropriate credit to the original author(s) and the source, provide a link to the Creative Commons license, and indicate if changes were made.

\section{Appendix}

See Table 2.

Table 2 Intended learning outcomes of the four PLC meetings, organized per domain of Magnusson et al. (1999)

Moment in PLC

Supporting literature

\section{M1: knowledge of goals and objectives}

There is a difference between doing research (objective, analyzing knowledge) and designing (subjective, solving a problem)

In O\&O projects, research and design complement each other, and can be combined by students and teachers

Doing research (gaining knowledge) is part of, and necessary for, designing

Designing without any form of research is intuitive design, and almost becomes art

When designing, one can also do research by testing and experimenting

Looking up knowledge relies on existing facts, and doing research is creating/synthesizing new knowledge yourself

Doing research or conducting a design request different skills

One can do research through design, when the design itself helps to provide knew knowledge

Design can enhance a research project when there is a 'need to do': for example, by designing an experimental setup

Basic knowledge about the research and design cycle(s)

The design cycle has multiple varieties, can be conducted more than once, is not linear, and has multiple dimensions

There are multiple research approaches: describing, explanatory, comparative, evaluative and design research

Knowing how to fine-tune a research question

After doing research, one can make a recommendation for the design of an application of the results 1st meeting, lecture $\mathrm{F}$

Vossen et al. (2018)

1st meeting, lecture TE

1st meeting, lecture TE

Sanders and Stappers (2008)

Frankel and Racine (2010)

1st meeting, lecture TE

De Jong and Van der Voordt (2002)

1st meeting, lecture TE

1st meeting, lecture TE

1st meeting, lecture TE

1st meeting, lecture TE

Frankel and Racine (2010)

1st meeting, oral explanation $\mathrm{F}$

1st meeting, lecture TE

1st meeting, lecture TE

Van Dooren et al. (2014)

1st meeting, lecture $\mathrm{F}$

1st meeting, lecture $\mathrm{F}$

1st meeting, oral explanation $\mathrm{F}$ 
Table 2 (continued)

Moment in PLC

Supporting literature

Reasons why it is important students learn about the connection between research and design

2nd meeting, collective CoRe

M2: knowledge of students

Knowledge of students' ideas about the connection between research

2nd meeting, collective CoRe and design

Knowledge of difficulties students may have when learning/applying the connection between research and design

Ideas about when (in which grade) students are mentally capable to learn about connection between research and design

M3: knowledge of instructional strategies

An O\&O project can be adjusted to include both research and design 3rd meeting components

The 'need to know' and 'need to do' can be made explicit in the O\&O project or by the teacher

2nd meeting, collective CoRe

Discussion in 1st meeting

Think of plug-in activities that can help enhance the connection between research and design in the O\&O lesson

Teachers test and apply these plug-ins

Teachers can evaluate applied plug-ins

3rd meeting

Kolodner, Gray, et al. (2003)

2nd meeting, collective CoRe and design of plug-ins

Between 2nd and 3rd meeting

3rd meeting, evaluation

Teacher know they can make explicit the connection between research Oral explanation $\mathrm{F}$ and design by denominating it to their students

Puntambekar and Hubscher (2005)

M4: knowledge of assessment

Teachers can think about ways to measure whether students have understood that a connection exists between research and design

2nd meeting, collective CoRe

\section{References}

Anderson, C. W. (2003). Teaching science for motivation and understanding. East Lansing: Michigan State University. Retrieved April 19, 2018, from www.msu.edu/ andya/TEScience/Assets/Files/TSMU.pdf.

Apedoe, X. S., Reynolds, B., Ellefson, M. R., \& Schunn, C. D. (2008). Bringing engineering design into high school science classrooms: The heating/cooling unit. Journal of Science Education and Technology, 17(5), 454-465.

Barendsen, E., \& Henze, I. (2017). Relating teacher PCK and teacher practice using classroom observation. Research in Science Education. https://doi.org/10.1007/s11165-017-9637-z.

Borko, H. (2004). Professional development and teacher learning: Mapping the terrain. Educational Researcher, 33(8), 3-15.

Borko, H., Mayfield, V., Marion, S., Flexer, R., \& Cumbo, K. (1997). Teachers' developing ideas and practices about mathematics performance assessment: Successes, stumbling blocks, and implications for professional development. Teaching and Teacher Education, 13(3), 259-278.

Burghardt, M. D., \& Hacker, M. (2004). Informed design: A contemporary approach to design pedagogy as the core process in technology. Technology Teacher, 64(1), 6-8.

Butler, D. L., Lauscher, N. H., Jarvis-Selinger, S., \& Beckingham, B. (2004). Collaboration and self-regulation in teachers' professional development. Teaching and Teacher Education, 20(5), 435-455.

Carlson, J. \& Daehler, K. R. (2019). The refined consensus model of pedagogical content knowledge in science education. In A. Hume, R. Cooper \& A. Boroswki (Eds.), Repositioning pedagogical content knowledge in teachers' professional knowledge (pp. 77-92). Singapore: Springer.

Clarke, D., \& Hollingsworth, H. (2002). Elaborating a model of teacher professional growth. Teaching and Teacher Education, 18(8), 947-967.

Coenders, F., Terlouw, C., Dijkstra, S., \& Pieters, J. (2010). The effects of the design and development of a chemistry curriculum reform on teachers' professional growth: A case study. Journal of Science Teacher Education, 21(5), 535-557. 
Creswell, J. W. (2007). Five qualitative approaches to inquiry. Qualitative Inquiry and Research Design, 2, 53-80.

Creswell, J. W. (2008). Educational research: Planning, conducting, and evaluating quantitative and qualitative research (3rd ed.). Upper Saddle River: Pearson.

Crismond, D. P., \& Adams, R. S. (2012). The informed design teaching and learning matrix. Journal of Engineering Education, 101(4), 738-797.

De Jong, T., \& Van der Voordt, T. (2002). Criteria for scientific study and design. Ways to study and research (pp. 19-32). Delft: DUP Science Publishers.

De Vries, M. J. (2005). Teaching about technology: An introduction to the philosophy of technology for nonphilosophers (Vol. 27). Springer.

De Vries, M. J. (2006). Two decades of technology education in retrospect. In M. J. de Vries \& I. Mottier (Eds.), International handbook of technology education: Reviewing the past twenty years (pp. 3-11). Rotterdam, Taipei: Sense Publishers.

De Vries, M. J. (2015). Research challenges for the future. In P. J. Williams, A. Jones, \& C. Buntting (Eds.), The future of technology education (pp. 253-269). Dordrecht: Springer.

Downton, P. (2003). Design research. Melbourne: RMIT University Press.

Doyle, A., Seery, N., Gumaelius, L., Canty, D., \& Hartell, E. (2018). Reconceptualising PCK research in D\&T education: proposing a methodological framework to investigate enacted practice. International Journal of Technology and Design Education. https://doi.org/10.1007/s10798-018-9456-1.

Engelbrecht, W., \& Ankiewicz, P. (2016). Criteria for continuing professional development of technology teachers' professional knowledge: A theoretical perspective. International Journal of Technology and Design Education, 26(2), 259-284.

Faikhamta, C. (2013). The development of in-service science teachers' understandings of and orientations to teaching the nature of science within a PCK-based NOS course. Research in Science Education, 43(2), $847-869$.

Fallman, D. (2003). Design-oriented human-computer interaction. In Proceedings of the SIGCHI conference on human factors in computing systems (pp. 225-232). ACM.

Franke, M. L., Carpenter, T. P., Levi, L., \& Fennema, E. (2001). Capturing teachers' generative change: A follow-up study of professional development in mathematics. American Educational Research Journal, 38, 653-689.

Frankel, L., \& Racine, M. (2010). The complex field of research: For design, through design, and about design. In Proceedings of the Design Research Society (DRS) international conference (No. 043).

Gess-Newsome, J. (1999). Secondary teachers' knowledge and beliefs about subject matter and their impact on instruction. In J. Gess-Newsome \& N. G. Lederman (Eds.), Examining pedagogical content knowledge (pp. 51-94). Dordrecht: Kluwer Academic Publishers.

Gess-Newsome, J. (2015). A model of teacher professional knowledge and skill including PCK: Results of the thinking from the PCK Summit. In A. Berry, P. Friedrichsen, \& J. Loughran (Eds.), Re-examining pedagogical content knowledge in science education. London: Routledge.

Gunckel, K. L. (2010). Using experiences, patterns, and explanations to make school science more like scientists' science. Science and Children, 48(1), 46-49.

Hathcock, S. J., Dickerson, D. L., Eckhoff, A., \& Katsioloudis, P. (2015). Scaffolding for creative product possibilities in a design-based STEM activity. Research in Science Education, 45(5), 727-748.

Henze, I., van Driel, J. H., \& Verloop, N. (2007). Science teachers' knowledge about teaching models and modelling in the context of a new syllabus on public understanding of science. Research in Science Education, 37(2), 99-122.

Henze, I., Van Driel, J. H., \& Verloop, N. (2008). Development of experienced science teachers' pedagogical content knowledge of models of the solar system and the universe. International Journal of Science Education, 30(10), 1321-1342.

Hsieh, H. F., \& Shannon, S. E. (2005). Three approaches to qualitative content analysis. Qualitative Health Research, 15(9), 1277-1288.

Hultén, M., \& Björkholm, E. (2016). Epistemic habits: primary school teachers' development of pedagogical content knowledge (PCK) in a design-based research project. International Journal of Technology and Design Education, 26(3), 335-351.

International Technology Education Association (ITEA). (2007). Standards for technological literacy: Content for the study of technology (3rd ed.). Reston, VA: International Technology Education Association (ITEA).

Jones, M. G., \& Legon, M. (2014). Teacher attitudes and beliefs: Reforming practice. In N. Lederman \& S. Abell (Eds.), Handbook of research on science teaching (pp. 830-847). New York: Routledge. 
Justi, R., \& Van Driel, J. (2005). The development of science teachers' knowledge on models and modelling: Promoting, characterizing, and understanding the process. International Journal of Science Education, 27(5), 549-573.

Kagan, D. M. (1990). Ways of evaluating teacher cognition: Inferences concerning the Goldilocks Principle. Review of Educational Research, 60, 419-469.

Käpylä, M., Heikkinen, J. P., \& Asunta, T. (2009). Influence of content knowledge on pedagogical content knowledge: The case of teaching photosynthesis and plant growth. International Journal of Science Education, 31(10), 1395-1415.

Kolodner, J. L., Camp, P. J., Crismond, D., Fasse, B., Gray, J., Holbrook, J., et al. (2003a). Problem-based learning meets case-based reasoning in the middle-school science classroom: Putting learning by design (tm) into practice. The Journal of the Learning Sciences, 12(4), 495-547.

Kolodner, J. L., Gray, J., \& Fasse, B. B. (2003b). Promoting transfer through case-based reasoning: Rituals and practices in learning by design classrooms. Cognitive Science Quarterly, 3(2), 119-170.

Leinhardt, G., \& Greeno, J. G. (1986). The cognitive skill of teaching. Journal of Educational Psychology, $78,75-95$.

Lewis, H. (1990). A question of values. San Francisco: Harper \& Row.

Loughran, J. J., Berry, A., \& Mulhall, P. (2006). Understanding and developing science teachers' pedagogical content knowledge. Rotterdam: Sense Publishers.

Love, T. S., \& Wells, J. G. (2018). Examining correlations between preparation experiences of US technology and engineering educators and their teaching of science content and practices. International Journal of Technology and Design Education, 28(2), 395-416.

Magnusson, S., Krajcik, J., \& Borko, H. (1999). Nature, sources, and development of pedagogical content knowledge for science teaching. In J. Gess-Newsome \& N. G. Lederman (Eds.), Examining pedagogical content knowledge (pp. 95-132). Dordrecht: Springer.

Mehalik, M. M., Doppelt, Y., \& Schuun, C. D. (2008). Middle-school science through design-based learning versus scripted inquiry: Better overall science concept learning and equity gap reduction. Journal of Engineering Education, 97(1), 71-85.

Mulhall, P., Berry, A., \& Loughran, J. (2003). Frameworks for representing science teachers' pedagogical content knowledge. In Asia-Pacific forum on science learning and teaching (Vol. 4, No. 2, pp. 1-25). Department of Science and Environmental Studies, The Education University of Hong Kong.

National Research Council (NRC). (2012). A framework for K-12 science education: Practices, crosscutting concepts, and core ideas. National Academies Press. Retrieved February 2, 2015, from https://www. nap.edu/catalog/13165/a-framework-for-k-12-science-education-practices-crosscutting-concepts.

NGSS Lead States. (2013). Next generation science standards: For states, by states. National Academies Press. Retrieved November 26, 2014, from https://www.nap.edu/catalog/18290/next-generation-scien ce-standards-for-states-by-states.

Pajares, M. F. (1992). Teachers' beliefs and educational research: Cleaning up a messy construct. Review of Educational Research, 62(3), 307-332.

Park, S., \& Chen, Y.-C. (2012). Mapping out the integration of the components of pedagogical content knowledge (PCK): Examples from high school biology classrooms. Journal of Research in Science Teaching, 49(7), 922-941.

Puntambekar, S., \& Hubscher, R. (2005). Tools for scaffolding students in a complex learning environment: What have we gained and what have we missed? Educational Psychologist, 40(1), 1-12.

Richardson, V. (1996). The role of attitudes and beliefs in learning to teach. In J. Sikula (Ed.), Handbook of research on teacher education (pp. 102-119). New York: Macmillan.

Rokeach, M. (1968). Beliefs, attitudes, and values: A theory of organization and change. San Francisco, CA: Jossey Bass.

Rollnick, M., Toerien, R., \& Kind, V. (2017). The impact of a professional development intervention on teachers' knowledge of chemical equilibrium. Paper presented at the 12th conference of the European Science Education Research Association (ESERA), Dublin, Ireland.

Sanders, E. B. N., \& Stappers, P. J. (2008). Co-creation and the new landscapes of design. Co-design, 4(1), $5-18$.

Schneider, B. (2007). Design as practice, science and research. In R. Michel (Ed.), Design research now (pp. 207-218). Basel: Birkhäuser.

Shernoff, D. J., Sinha, S., Bressler, D. M., \& Ginsburg, L. (2017). Assessing teacher education and professional development needs for the implementation of integrated approaches to STEM education. International Journal of STEM Education, 4(1), 13.

Shulman, L. (1987). Knowledge and teaching: Foundations of the new reform. Harvard Educational Review, 57(1), 1-23. 
SLO (Nationaal Expertisecentrum Leerplanontwikkeling), Bruning, L. \& Michels, B. (2014). Handreiking schoolexamen Onderzoek \& ontwerpen in de tweede fase (Instruction manual for school exams Research \& design in upper secondary education). Retrieved February 6, 2019, from http://www.slo. nl/organisatie/recentepublicaties/handreikingonderzoek/.

Stohlmann, M., Moore, T. J., \& Roehrig, G. H. (2012). Considerations for teaching integrated STEM education. Journal of Pre-College Engineering Education Research, 2(1), 4.

Supovitz, J. A., \& Turner, H. M. (2000). The effects of professional development on science teaching practices and classroom culture. Journal of Research in Science Teaching, 37(9), 963-980.

Van Breukelen, D., Schure, F., Michels, K., \& de Vries, M. (2016). The FITS model: An improved learning by design approach. Australasian Journal of Technology Education, 3(1).

Van Dooren, E., Boshuizen, E., van Merriënboer, J., Asselbergs, T., \& van Dorst, M. (2014). Making explicit in design education: Generic elements in the design process. International Journal of Technology and Design Education, 24(1), 53-71.

Van Driel, J. H., Beijaard, D., \& Verloop, N. (2001). Professional development and reform in science education: The role of teachers' practical knowledge. Journal of Research in Science Teaching, 38(2), 137-158.

Van Driel, J. H., Verloop, N., \& de Vos, W. (1998). Developing science teachers' pedagogical content knowledge. Journal of research in Science Teaching, 35(6), 673-695.

Veal, W. R. (2004). Beliefs and knowledge in chemistry teacher development. International Journal of Science Education, 26(3), 329-351.

Vezino, B. (2018). Preservice and mentor teachers co-learning to teach engineering in elementary classrooms. Students' attitudes towards doing research and design activities. Paper presented at the National Association for Research in Science Teaching (NARST) 2018 Annual International Conference, Atlanta, USA.

Vossen, T. E., Henze, I., Rippe, R. C. A., Van Driel, J. H., \& De Vries, M. J. (2018). Attitudes of secondary school students towards doing research and design activities. International Journal of Science Education, 40(13), 1629-1652.

Wahbeh, N., \& Abd-El-Khalick, F. (2014). Revisiting the translation of nature of science understandings into instructional practice: Teachers' nature of science pedagogical content knowledge. International Journal of Science Education, 36(3), 425-466.

Williams, J., Eames, C., Hume, A., \& Lockley, J. (2012). Promoting pedagogical content knowledge development for early career secondary teachers in science and technology using content representations. Research in Science \& Technological Education, 30(3), 327-343.

Willison, J., \& O'Regan, K. (2008). The researcher skill development framework. Retrieved January 14, 2016, from https://www.adelaide.edu.au/rsd/framework/rsd7/.

Publisher's Note Springer Nature remains neutral with regard to jurisdictional claims in published maps and institutional affiliations.

\section{Affiliations}

\section{T. E. Vossen ${ }^{1,2}$ (1) $\cdot$ I. Henze ${ }^{2} \cdot$ M. J. De Vries ${ }^{2} \cdot$ J. H. Van Driel ${ }^{1,3}$}

I. Henze

f.a.henze-rietveld@ @udelft.nl

M. J. De Vries

M.J.deVries@tudelft.nl

J. H. Van Driel

j.vandriel@unimelb.edu.au

1 Leiden University Graduate School of Teaching, Leiden University, Kolffpad 1, P.O. Box 905, 2300 AX Leiden, The Netherlands

2 Department of Science Education and Communication, Delft University of Technology, Lorentzweg 1, 2628 CJ Delft, The Netherlands

3 Melbourne Graduate School of Education, The University of Melbourne, 234 Queensberry St, Melbourne 3010, VIC, Australia 